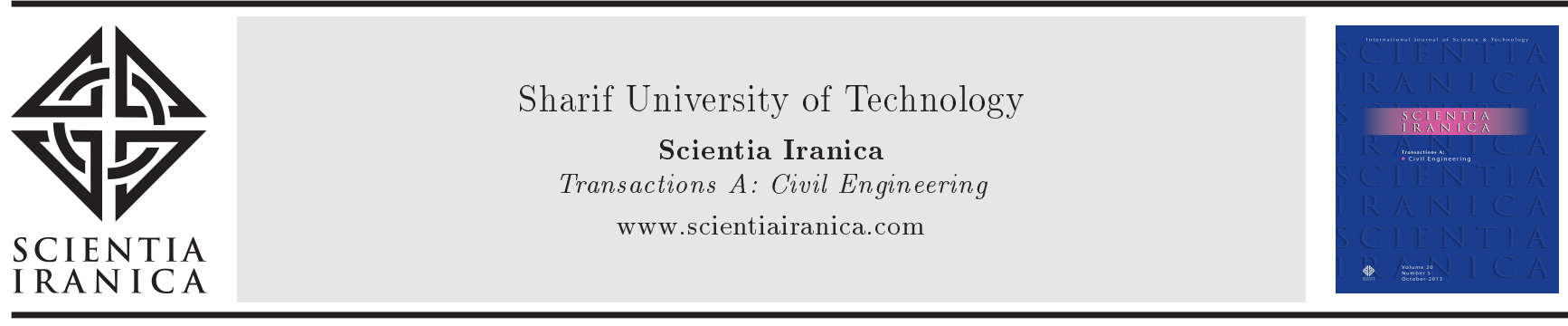

\title{
Increasing the flexural capacity of geopolymer concrete beams using partial deflection hardening cement-based layers: A numerical study
}

\author{
M. Mastalia,*, M. Mastali ${ }^{\mathrm{b}}$, Z. Abdollahnejad ${ }^{\mathrm{c}}$ and A. Dalvand ${ }^{\mathrm{d}}$ \\ a. ISISE, Department of Civil Engineering, University of Minho, 4800-058 Guimaraes, Portugal. \\ b. Faculty of Civil Engineering, Western Michigan University, Kalamazoo, MI 49008-5316, USA. \\ c. C-TAC Research Centre, Department of Civil Engineering, University of Minho, 4800-058 Guimaraes, 4800-058, Portugal. \\ d. Department of Engineering, Lorestan University, Khorramabad, Iran.
}

Received 23 April 2016; received in revised form 19 June 2016; accepted 21 November 2016

\author{
KEYWORDS \\ FEM; \\ Material nonlinear \\ analysis; \\ Flexural \\ strengthening; \\ DHCC; \\ Enlargement method.
}

\begin{abstract}
Experimental research has demonstrated the great flexural performance of deflection hardening cement-based composites for strengthening the beams. This paper numerically investigates the feasibility of adding thin deflection hardening fiber-reinforced layers to the bottom of geopolymer concrete beams to enhance the flexural performance. To properly predict the structural behavior and crack patterns of beams, the smeared crack approach was adopted to simulate the beams. The numerical simulations were executed in the FEM-based computer program. To validate the developed numerical models, the experimental test beams were numerically simulated with a cross section of two layers. Regarding the results obtained, the models would well predict the structural behavior and crack patterns of beams. To ensure the efficiency and accuracy of the adopted constitutive model in predicting the structural behavior and crack patterns of beams, the numerical FE models were used to simulate the added hardening deflection fiber-reinforced layer to the bottom of geopolymer concrete beams. The numerical results revealed that adding a thin fiber-reinforced layer to geopolymer concrete beams resulted in increasing ultimate load capacity, ultimate deflection, and ductility. The greatest enhancement in the flexural performance of the strengthened beams was found in the ultimate load capacity of the strengthened beams.
\end{abstract}

(C) 2017 Sharif University of Technology. All rights reserved.

\section{Introduction}

In the last two decades, consumption of concrete as the most widely used building material in the world has significantly increased; it is estimated that the demand of Ordinary Portland Cement (OPC) will reach the total of $6 \mathrm{Gt} /$ year up to the year 2050 [1]. High levels of carbon dioxide $\left(\mathrm{CO}_{2}\right)$ gas are emitted during cement

*. Corresponding author.

E-mail address: m.mastali@civil.uminho.pt (M. Mastali)

doi: $10.24200 /$ sci. 2017.4530 production. Massive emissions of carbon dioxide bring serious environmental problems for humans. Therefore, despite good mechanical and durability properties of the concrete made with OPC, in the last decade, some environmentally friendly alternatives like geopolymers (also termed alkali-activated binders) have recently been developed to replace with the OPC in concrete. In 1990, geopolymer concrete was developed as an environmentally friendly alternative to Portland cement by Davidovits et al. [2]. These binders emit much lower carbon dioxide than the concrete made with Portland cement does (0.184 tons of $\mathrm{CO}_{2}$ per ton of binder) [2] The main problem with plain concrete made with 
OPC, in addition to massive emissions of toxic gas, is low ductility and load-carrying capacity under the imposed loads. This problem also exists in plain concrete with alkali-activator binders.

Section enlargement is one of the effective strengthening techniques, which is used to improve structural behavior of Reinforced Concrete (RC) elements. In this technique, an external layer is attached to the element to enhance the structural performance under the imposed loads. The external layer would be a thin fiber-reinforced concrete layer. Much research has been conducted to assess the efficiency of this technique in strengthening $\mathrm{RC}$ elements. Previous studies in [3-7] demonstrated that this strengthening technique had significant effects on enhancing the structural performance of repaired elements.

Fiber-Reinforced Cementitious Composite (FRCC) is a term commonly used for a broad class of materials. Every FRCC consists of two basic components; a cementitious-based material, called matrix, and steel or synthetic fibers, which reinforce the matrix. The most widely accepted proposition is to classify FRCCs by their stress-strain response in direct tension and load-deflection response in flexure. Some FRCCs (Fiber Reinforced Cementitious Composites) are not strain hardening in direct tension, but can present a hardening behavior in flexure. These materials are called deflection hardening FRCCs and are categorized as Deflection Hardening Cement Composites (DHCC). The DHCC material offers highly ductile behavior due to bridging action of fibers, which enables the formation of multiple cracks on the tensile surface. Fiber bridging action is capable of arresting further opening of cracks and, as a result, new cracks tend to form in the close vicinity [8]. On the opposite, plain mortar presents very brittle behavior and forming the first crack leads to failure, as shown in Figure 1(a).

Like plain concrete made with OPC, the geopolymer concrete has low ductility and load-carrying capacity. Therefore, with respect to the low ductility and load-carrying capacity of the structural elements made with plain geopolymer concrete, this paper numerically establishes and investigates the feasibility of adding a thin deflection hardening fiber-reinforced layer to the bottom of beams made with geopolymer concrete to increase their ductility and their ultimate load-carrying capacity.

In the first phase of this paper, a brief explanation is presented on the mechanical properties of the thin fiber-reinforced mortar layers being used to strengthen the geopolymer concrete beams. These mechanical properties also include the flexural and compressive strengths. In addition, the flexural performances of three beams made with plain geopolymer concrete are assessed under Three-Point Bending (TPB) tests.

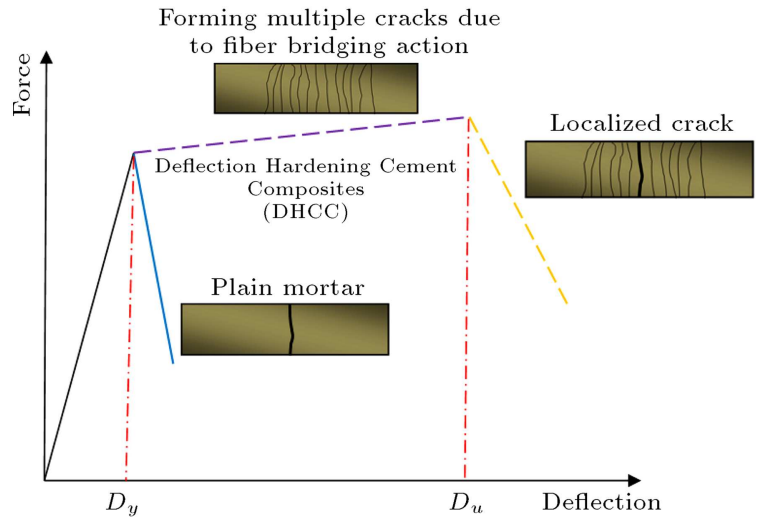

(a)

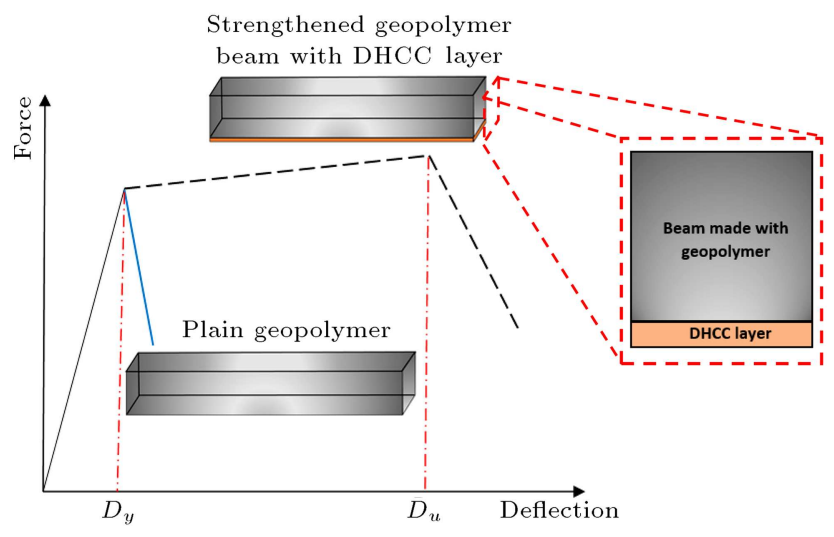

(b)

Figure 1. (a) Force vs. deflection response of fiber-reinforced and plain mortars. (b) Using enlarged cross section to improve flexural performance of plain geopolymer concrete beams.

Then, the strategy adopted to strengthen the geopolymer concrete beams with adding deflection hardening fiber-reinforced layers is described.

As the beams are numerically strengthened, in the second stage of this paper, a brief explanation is presented on the constitutive models adopted for simulating thin fiber-reinforced layers and beams made with geopolymer concrete. Afterward, to assess the efficiency and accuracy of the constitutive models used in predicting structural behavior and in capturing the failures, the experimental results obtained in [5] are employed to calibrate the numerical Finite Element (FE) models. After assuring the efficiency of the proposed numerical models in predicting the structural behavior and failure modes of beams, the thin fiberreinforced layers and beams made with geopolymer concrete are numerically modeled and the numerical FE models are calibrated based on the experimental results.

Finally, thin fiber-reinforced layers are added to the bottom surface of beams made with geopolymer concrete and the effects of this strengthening method 
on the ductility and load-carrying capacity of beams are investigated.

\section{Experimental program}

An experimental study was carried out in [9] to develop hardening deflection cement-based mortars using glass fiber under flexural load condition. Two types of glass fiber with different volumes of $1 \%, 1.5 \%$, and $2 \%$ were used to reinforce the matrix. 270 specimens were experimentally tested, including 162 cubic specimens and 108 beams, for assessing the compressive and flexural performances of specimens, respectively. A distributed load was imposed on the beams in order to provide flexural loading. Moreover, deflections at midspan of beams were recorded by using a Linear Variable Differential Transformer (LVDT) with $50 \mathrm{~mm}$ of stroke. More details about experimental tests and results can be found in [9]. Concerning the results obtained, based on type of fiber, fiber content, and mix composition, some specimens showed deflection hardening or softening behavior under the flexural loading. The reinforced mixture with deflection hardening behavior was capable to increase the ultimate load-carrying capacity and deflection of the strengthened RC elements [35]; therefore, the reinforced mix compositions with deflection hardening behavior were selected from this experimental program to strengthen the beams made with geopolymer concrete. The flexural performance of the selected beams is depicted in Figure 2. In nomi-

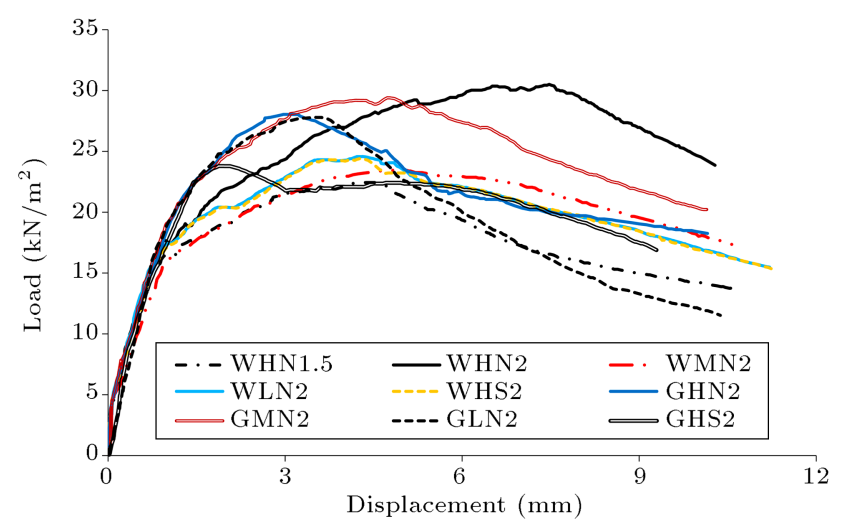

Figure 2. Deflection hardening behavior of reinforced mixtures [9]. nation process of specimens, the first letter represents type of cement ("W" and "G" stand for white and gray cement, respectively). The second letter indicates the content of cement ("H", "M", and "L" refer to high $\left(900 \mathrm{~kg} / \mathrm{m}^{3}\right)$, medium $\left(800 \mathrm{~kg} / \mathrm{m}^{3}\right)$, and low $(700$ $\mathrm{kg} / \mathrm{m}^{3}$ ) contents of cement, respectively). The third and last letter shows the type and content (Vol. \%) of the used fiber ("N" and "S" represent Neg and Simona fibers, respectively). Both types of fibers had $12 \mathrm{~mm}$ of length, $1.2 \mathrm{~mm}$ of diameter, and similar mechanical properties; however, the Neg and Simona fibers were produced by a Japanese company and a Chinese one, respectively. Some cracks formed on the tensile surface of the fiber-reinforced specimens. In this case, the formation of more numbers of cracks indicates higher effectiveness of fiber bridging action in arresting the further cracks.

Furthermore, to assess the flexural performance of beams made with geopolymer concrete, three beams of $1000 \times 100 \times 100 \mathrm{~mm}$ were cast and cured for 28 days. The ingredients of the mixed geopolymer composition consisted of kaolin, fly ash, Ordinary Portland Cement (OPC), sodium hydroxide, calcium hydroxide $\left(\mathrm{Ca}(\mathrm{OH})_{2}\right)$, water, and superplasticizer. More details about mix design and procedure of mixing can be obtained in [9]. The prismatic beams were tested under Three-Point Bending (TPB) loading. The test setup adopted and devices installed to measure mid-span deflection are depicted in Figure 3. Flexural tests were executed under displacement control at a displacement rate of $0.6 \mathrm{~mm} / \mathrm{min}$ at Minho University. Mid-span deflections were registered by an LVDT with $10 \mathrm{~mm}$ of stroke. The records showed that beams made with the geopolymer concrete had brittle behavior, as illustrated in Figure 4. It is worth mentioning that the presented result in Figure 4 is an average of three tested beams.

By forming the initial crack, the beams immediately entered into the structural softening behavior, which significantly reduced the load and deflection. By comparing ultimate load and deflection corresponding to the registered ultimate loads for beams made with the geopolymer concrete and fiber-reinforced cementbased composites in Figures 2 and 4, it is revealed that the reinforced thin panels with $40 \mathrm{~mm}$ of thickness have much higher ductility and load-carrying capacity,
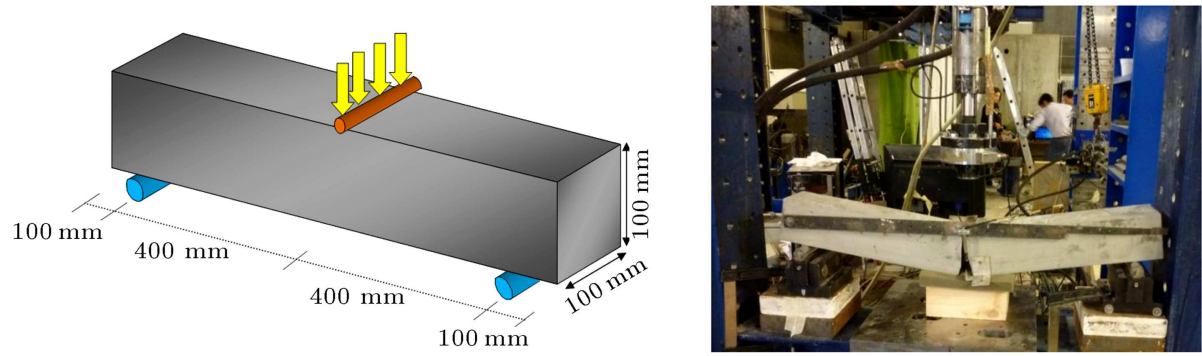

Figure 3. Adopted test setup and installed devices for flexural tests. 


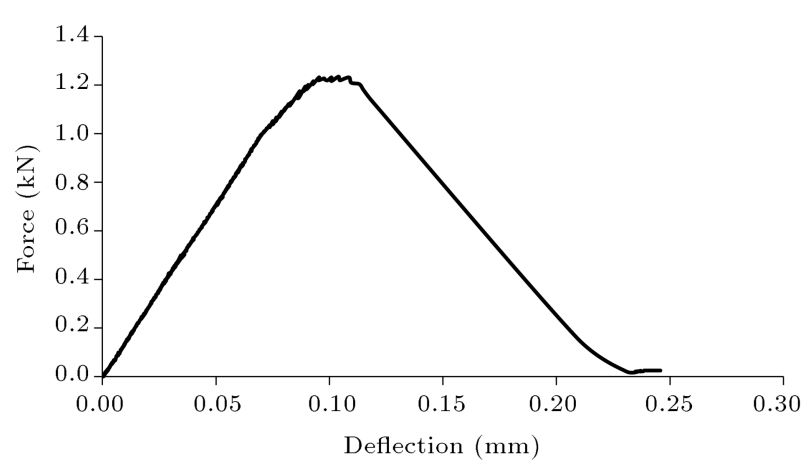

Figure 4. Force vs. deflection response of beams made with geopolymer concrete.

strongly depending on the fiber contents, fiber type, and mix compositions.

To obtain the compressive strength of geopolymer concrete, a compressive load with a displacement rate of $0.3 \mathrm{MPa} / \mathrm{sec}$ was imposed on five cubic specimens with dimensions of $100 \times 100 \times 100 \mathrm{~mm}$. With respect to the obtained results, an average compressive strength equal to $30 \mathrm{MPa}$ was measured for geopolymer concrete at 28 days of age.

\section{Adopted strategy for strengthening the geopolymer beams}

The developed thin DHCC plates showed deflection hardening behavior under flexural load conditions, while beams made with plain geopolymer concrete indicated brittle behavior under flexural load conditions. In this regard, the reinforced thin plates can be used for strengthening the weak beams against increase in the ultimate load and deflection under flexural loading. Forming the initial crack in the tensile zone and propagating the formed crack up to compression zone was the main reason of failure of beams made with plain concrete; therefore, reinforcing the tensile zone through using a thin reinforced cement-based layer can enhance the flexural performance of beams made with plain geopolymer concrete. This improvement can significantly be attained in flexural performance of the DHCC layer. As indicated in Figure 1(b), reinforcement of tensile zone of the beams can increase ductility and the ultimate load-carrying capacity under flexural loading. Mechanism of fiber bridging action in the reinforced thin layer and forming multiple cracks on the tensile surface of DHCC layer results in increase in the ultimate tensile capacity of composite beams at the tensile zone. This increase will lead to formation of more cracks in the beams made with plain geopolymer concrete.

\section{Nonlinear finite element modeling}

In the present paper, the efficiency of using an en-

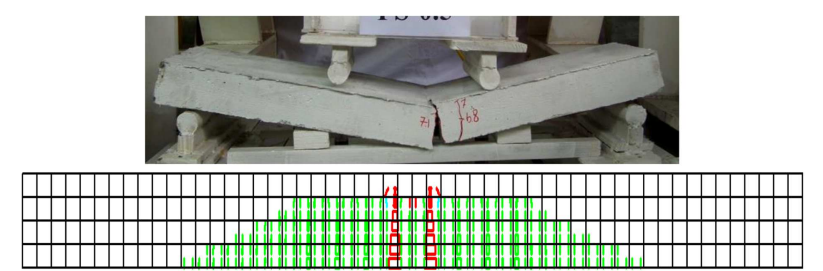

(a)

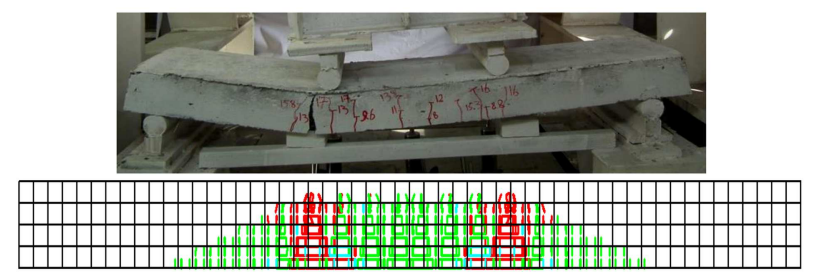

(b)

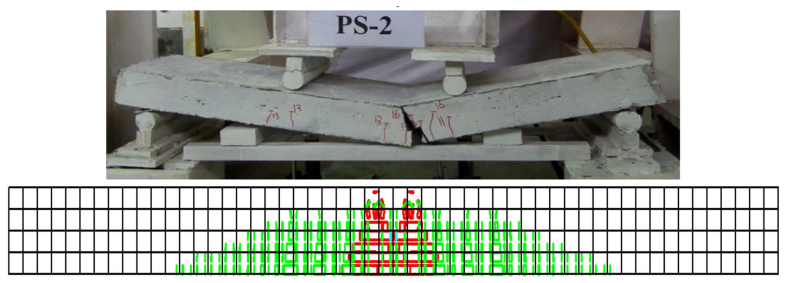

(c)

Figure 5. Comparison of the formed crack patterns in the numerical simulations and experimental results in [5].

largement method in strengthening plain beams made with the geopolymer concrete was assessed through simulating numerical models in FEM-based software. Plain geopolymer concrete and DHCC layer were modeled by using multi-directional fix smeared crack constitutive model. In this model, the post-cracking behavior of reinforced cement-based specimens under tension can be taken into account by a trilinear stressstrain softening diagram. In the following, more details are provided about this constitutive model, which is used to simulate DHCC layers and plain geopolymer concrete. In 2008, Pereira et al. [10] indicated that fracture mode I propagation of fiber-reinforced concrete could be simulated by the trilinear diagram represented in Figure 5, and its parameters of fracture energy, including the ultimate crack strain, the fracture energy, the tensile strength, and the crack band width, could be obtained through execution of an inverse analysis by calibrating the numerical results with the forcedeflection data registered in the experimental tests [10].

\subsection{Multi-directional fixed smeared crack constitutive model}

Numerical simulations in this study were executed by using the FEMIX software, an FEM-based software program that is able to simulate nonlinear behavior of several types of materials $[11,12]$. This software was developed at Minho University. The multi-directional fixed smeared crack model was used to simulate the crack initiation and propagation of DHCC specimens 
in FEMIX 4.0 software of which a brief description is presented in the following.

In order to analyze the beams with Finite Element (FE) models, they were considered as plane stress problems. The explanation of the formulation of the multi-directional fixed smeared crack model is related to the case of cracked concrete in the domain of an Integration Point (IP). According to the adopted constitutive law for plane stress finite element, stress and strain are related to each other by:

$$
\Delta \sigma=D^{C r c o} \Delta \varepsilon
$$

where, $\Delta \sigma=\left\{\Delta \sigma_{1}, \Delta \sigma_{2}, \Delta \tau_{12}\right\}^{T}$ and $\Delta \varepsilon=\left\{\Delta \varepsilon_{1}\right.$, $\left.\Delta \varepsilon_{2}, \Delta \gamma_{12}\right\}^{T}$ are the components of stress and strain vectors, respectively. By decomposing the total strain in Eq. (1) into elastic and cracked concrete parts, i.e. $\Delta \varepsilon=\Delta \varepsilon^{e l a}+\Delta \varepsilon^{c r a}, D^{C r c o}$ will be determined using $[13,14]$ :

$$
\begin{gathered}
D^{C r c o}=D^{C o}-D^{C o}\left[T^{C r}\right]^{T}\left(D^{C r}+T^{C r} D^{C o}\left[T^{C r}\right]^{T}\right)^{-1} \\
T^{C r} D^{C o}
\end{gathered}
$$

where, $D^{C o}$ is the constitutive matrix of concrete assumed to have a linear behavior:

$$
D^{C o}=\frac{E_{c}}{1-\nu_{c}^{2}}\left[\begin{array}{ccc}
1 & \nu_{c} & 0 \\
v_{c} & 1 & 0 \\
0 & 0 & \frac{1-v_{c}}{2}
\end{array}\right]
$$

where $E_{C}$ and $\nu_{C}$ are elasticity modulus and Poisson's ratio of concrete, respectively. $T^{C r}$ in Eq. (2) is the transform matrix of stress components from the coordinate system of elements to local crack coordinate system. If $n$ is the number of cracks, $T^{C r}$ will be defined as:

$$
T^{C r}=\left[\begin{array}{lllll}
T_{1}^{C r} & \ldots & T_{i}^{C r} & \ldots & T_{n}^{C r}
\end{array}\right]^{T},
$$

where the crack orientation matrix is given by:

$$
T_{i}^{C r}=\left[\begin{array}{ccc}
\cos ^{2} \theta & \sin ^{2} \theta & 2 \sin \theta \cos \theta \\
-\sin \theta \cos \theta & \sin \theta \cos \theta & \cos ^{2} \theta-\sin ^{2} \theta
\end{array}\right]
$$

And $\theta$ is defined as the angle between the $x_{1}$ axis and the vector orthogonal to the plane of the $i$ th crack. Furthermore, $D^{C o}$ in Eq. (2) is defined as a matrix that includes the constitutive law of the $n$ cracks:

$$
D^{C r}=\left[\begin{array}{ccccc}
D_{1}^{C r} & \ldots & 0 & \ldots & 0 \\
\ldots & \ldots & \ldots & \ldots & \ldots \\
0 & \ldots & D_{i}^{C r} & \ldots & 0 \\
\ldots & \ldots & \ldots & \ldots & \ldots \\
0 & \ldots & 0 & \ldots & D_{n}^{C r}
\end{array}\right]
$$

In the above equation, $D_{i}^{C r}$ is the crack constitutive matrix of the $i$ th crack, which is defined as:

$$
\begin{aligned}
& D^{C r}=\left[\begin{array}{cc}
D_{I, i}{ }^{C r} & 0 \\
0 & D_{I I, i}{ }^{C r}
\end{array}\right] \\
& D_{I, i}{ }^{C r}=-k_{i} \frac{{ }_{C r} f_{c t}^{2}}{G_{f}} \\
& k_{1}=\frac{\left(1-\alpha_{1}\right)\left(\xi_{1}+\alpha_{1} \xi_{2}-\alpha_{2} \xi_{1}+\alpha_{2}\right)}{2 \xi_{1}}, \\
& k_{2}=\frac{\left(\alpha_{1}-\alpha_{2}\right)\left(\xi_{1}+\alpha_{1} \xi_{2}-\alpha_{2} \xi_{1}+\alpha_{2}\right)}{2\left(\xi_{2}-\xi_{1}\right)}, \\
& k_{3}=\frac{\alpha_{2}\left(\xi_{1}+\alpha_{1} \xi_{2}-\alpha_{2} \xi_{1}+\alpha_{2}\right)}{2\left(1-\xi_{1}\right)},
\end{aligned}
$$

where, $D_{I, i}^{C r}$ and $D_{I I, i}^{C r}$ are the moduli corresponding to the fracture mode I (normal) and fracture mode II (shear) of the $i$ th crack, respectively. In this numerical approach, a new crack forms in an Integration Point (IP) when the angle between the new crack and the already existing cracks exceeds a certain threshold angle (this angle is selected between 30-60 degrees according to [13]). The crack opening propagation was simulated using the trilinear diagram, which is indicated in Figure 6. Normalized stresses $\left(\alpha_{1}\right.$ and $\alpha_{2}$ ) and strains $\left(\xi_{1}\right.$ and $\left.\xi_{2}\right)$ were defined and used for transposition points between the linear segments of the diagram. The ultimate crack strain $\left(\varepsilon_{n, u}^{C r}\right)$ is a function of the fracture energy, tensile strength $\left(\sigma_{n, 1}^{C r}=f_{c t}\right)$, crack bandwidth $\left(l_{C r}\right)$, and normalized strains and stresses. Thus, the ultimate crack strain is given by [13]:

$$
\varepsilon_{n}^{C r}=\frac{2}{\xi_{1}+\alpha_{1} \xi_{2}-\alpha_{2} \xi_{1}+\alpha_{2}}\left(\frac{G_{f}}{l_{C r} \sigma_{t}^{C r}}\right),
$$

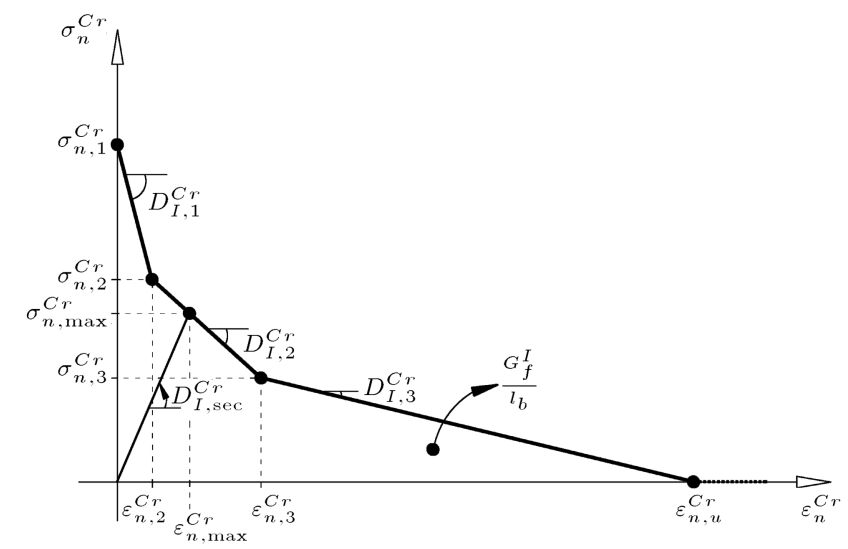

Figure 6. Trilinear stress-strain diagram to simulate the fracture mode I crack propagation $\left(\sigma_{n, 1}^{C r}=f_{c t}\right.$, $\left.\sigma_{n, 2}^{C r}=\alpha_{1} \sigma_{n, 1}^{C r}, \sigma_{n, 3}^{C r}=\alpha_{2} \sigma_{n, 1}^{C r}, \varepsilon_{n, 2}^{C r}=\xi_{1} \varepsilon_{n, u}^{C r}, \varepsilon_{n, 3}^{C r}=\xi_{2} \varepsilon_{n, u}^{C r}\right)$. 


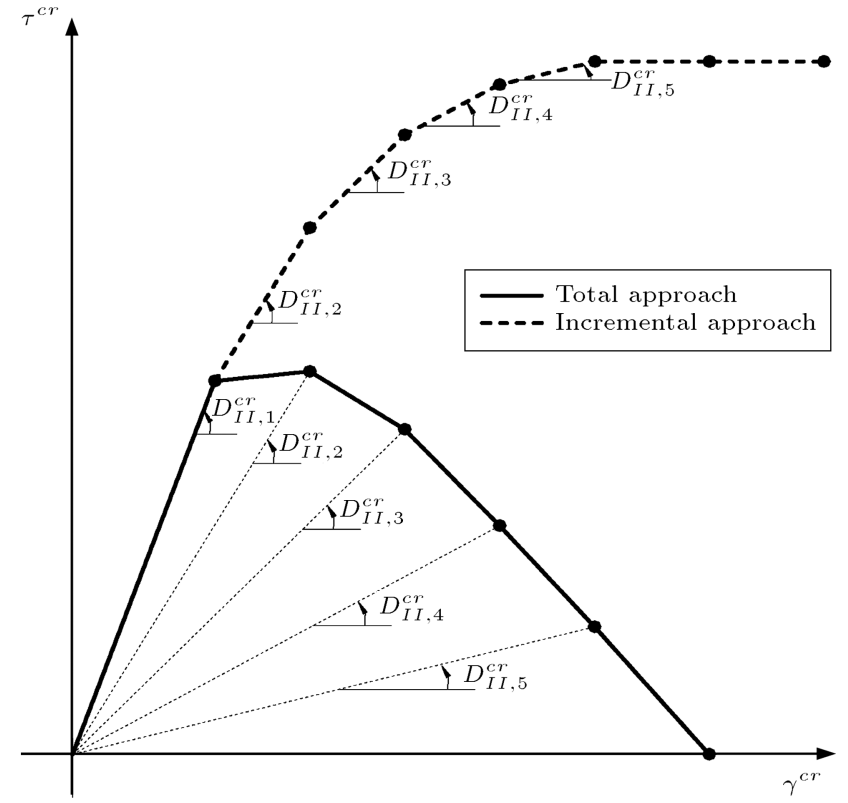

Figure 7. Relation between crack shear stress and crack shear strain for the incremental and total approaches.

and the fracture mode II modulus, $D_{I I}^{C r}$, is defined by [13]:

$$
D_{I I}^{C r}=\frac{\kappa}{1-\kappa} G_{C}
$$

where, $G_{C}$ is the elastic concrete shear modulus and $\kappa$ is the shear retention factor. The parameter $\kappa$ is considered as a function of the current crack normal strain $\left(\varepsilon^{C r}\right)$ and ultimate crack normal strain $\left(\varepsilon_{n}\right)^{C r}[15]$ :

$$
\kappa=\left(1-\frac{\varepsilon^{C r}}{\varepsilon_{n}^{C r}}\right)^{P_{1}},
$$

where, $P_{1}$ is a parameter to define the decrease rate of $k$ with increase in the crack normal strain component $\left(\varepsilon^{C r}\right)$. In this study, the value of $P_{1}$ was considered equal to 2 [11]. Regarding fracture mode II, the total and the incremental approaches, depicted in Figure 7, and more details, explained in [14], are available in FEMIX; however, in the implemented numerical simulations, the total approach was adopted due to its better performance.

\section{Validation of numerical FE models}

In this section, the experimental results obtained in [3] are used to assess the numerical FE models. The main aim was to assess the feasibility of using a perfect bond for modeling the transition layer between two different concrete layers. Since there was no specific bond behavior for modeling transition zone between two-layer concrete, the experimental results of some tested two-layer beams were used in this study to investigate the feasibility of using perfect bond for modeling the transition layer between two different concrete layers. This assessment was carried out by validating force-deflection response of beams and the crack patterns formed in the experimental results and numerical simulations.

Ghasemi Naghibdehi et al. experimentally investigated the flexural performance of beams with twolayer reinforced concrete [5]. Concrete at top and bottom layers of beams was reinforced by polypropylene fiber and steel fiber, respectively. Different fiber volume fractions were used to reinforce the concrete, including $0.5 \%, 1 \%$, and $2 \%$. The beams with $1200 \mathrm{~mm}$ of span length and cross section equal to $(300 \times 100 \mathrm{~mm})$ underwent four-point bending test, as indicated in Figure 8. Flexural tests were carried out under displacement control at a displacement rate of $10 \mu \mathrm{m} / \mathrm{min}$.

In this section, the beams in [5] are modeled with a mesh of 8-node serendipity plane stress finite elements. The Gauss-Legendre integration scheme with $2 \times 2$ integration points was used in all elements, with the exception of the elements at the specimen symmetry axis, where $1 \times 2$ integration points were used to assure that the crack progressed along the symmetry axis of the specimen. Properties adopted to simulate the nonlinear behavior of the reinforced concrete layers of beams are listed in Table 1 . In the experimental tests, flexural load was imposed on the beams using two load lines with $40 \mathrm{~mm}$ of width and $300 \mathrm{~mm}$ of length. This load line was located at $400 \mathrm{~mm}$ of distance from each support, as indicated in Figure 8. In the numerical simulation, a load line with $40 \mathrm{~mm}$ of width was imposed on the beams at $400 \mathrm{~mm}$ of distance from each support. The supports of the beams were restricted by the points with null displacements in the vertical direction $(Z)$. Moreover, supports indicated in the left side in Figure 8 were restricted by the points with null displacements in $Y$ direction.

The results presented in $[3,4,16]$ revealed that there was no slippage between the different layers and shear stresses were transferred continuously between the cementitious composite transition layers. Iskhakov et al. reported that no horizontal cracks were observed in the two-layer beams up to the Ultimate Limit State (ULS), which demonstrated strong bond formation between the cementitious composite transition layers [4].

Martinola et al. used a cementitious jacket made of fiber-reinforced concrete with tensile hardening behavior for strengthening RC beams [17]. The developed fiber-reinforced concrete had the flexural strength of about $23 \mathrm{MPa}$ at mid-span deflection of $0.6 \mathrm{~mm}$, as well as tensile strength of about $11 \mathrm{MPa}$ with strain hardening of about $0.4 \%$. The cementitious jacket made with fiber-reinforced concrete was externally attached to $\mathrm{RC}$ beams for repairing and strengthening of the structural elements [17]. Based on the obtained 
Cross section of two-layer beams

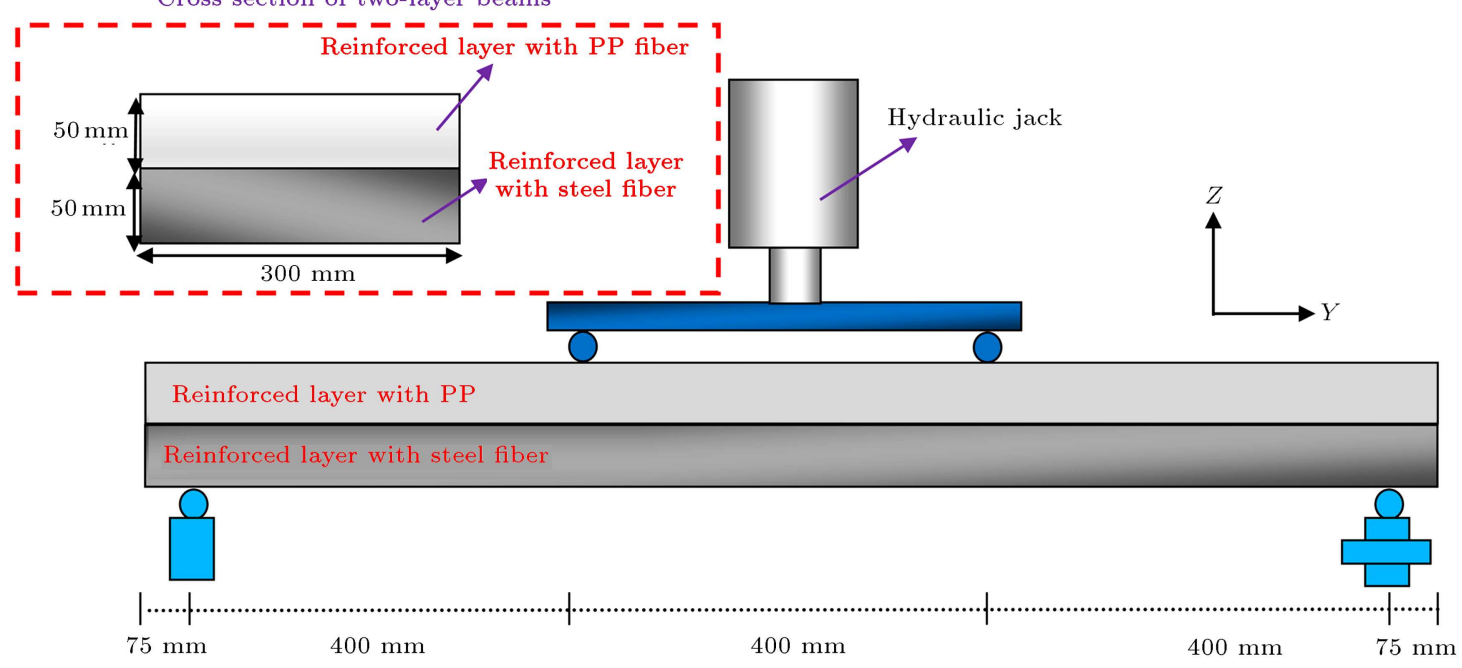

Figure 8. Adopted test setup for execution of FPB test in [5].

Table 1. Adopted parameters to simulate the nonlinear behavior of RC layers.

\begin{tabular}{|c|c|c|c|}
\hline & PS0.5 & PS1 & PS2 \\
\hline & $\mathbf{S S}^{* *}$ & $\mathbf{P P}$ & $\mathbf{P P}$ \\
\hline Poisson's ratio $\left(v_{C}\right)$ & 0.15 & 0.15 & 0.15 \\
\hline Initial Young's modulus (GPa) [5] & 18.42 & 18.42 & 15.00 \\
\hline Compressive strength (MPa) [5] & $49.36 \quad 46.9$ & $49.36 \quad 46.9$ & 49.36 \\
\hline $\begin{array}{l}\text { Maximum number of cracks in an } \\
\text { integration point (IP) }[12,14]\end{array}$ & 2 & 2 & 2 \\
\hline $\begin{array}{l}\text { Parameter defining the mode I fracture } \\
\text { energy available to the new crack (P1) [14] }\end{array}$ & 2 & 2 & 2 \\
\hline Shear retention factor (exponential) $[12,14]$ & 2 & 2 & 2 \\
\hline Crack band-width, $l_{C r}[12,14]$ & $\sqrt{ } A i$ & $\sqrt{ } A i$ & $\sqrt{ } A i$ \\
\hline Threshold angle, $\alpha$ th $[12,14]$ & 30 & 30 & 30 \\
\hline
\end{tabular}

results from experimental tests in [17], to implement numerical simulation of the strengthened beams, the cementitious jacket was attached to RC beams with perfect bond [17]. In 2013, Loreto et al. used fiberreinforced cementitious mortars for strengthening of existing RC slab-type elements [18]. They found that there was no slippage between fiber-reinforced cementitious layer and RC slab up to the ultimate load capacity [18]. Larbi et al. experimentally and numerically investigated the repairing/strengthening of RC beams by using TRC (Textile-Reinforced Concrete) and hybrid (TRC + carbon and glass rods) solutions [19]. In the numerical simulation, perfect bond was used to model interface between $\mathrm{RC}$ beams and the proposed solutions, including TRC and hybrid [19]. In 2011, Vasconcelos et al. investigated the use of metakaolin-based geopolymer mortars for retrofitting purposes [20]. They strengthened concrete beams with thin geopolymer mortar plates. The thin plates were attached to concrete beams by using CFRP sheets. The experimental results showed a low adhesive strength at the transition zone among tension surface of concrete beam, CFRP sheet, and geopolymer mortar plates [20].

With respect to the previous studies, a perfect bond was considered to model the transaction layer between two layers of the tested beams and the feasibility of using perfect bond for modeling the transition layer was assessed by comparing the structural behavior and the formed crack patterns in experimental tests and numerical simulations.

\subsection{Evaluation of FE models with experimental results}

The inverse analysis was carried out by FEMIX software to obtain the parameters of trilinear stress-strain diagram to simulate crack propagation in fracture 
Table 2. The obtained parameters of fracture mode I crack.

\begin{tabular}{cccccccc}
\hline Multi layers & Layer positions & $\boldsymbol{\alpha}_{\mathbf{1}}$ & $\boldsymbol{\alpha}_{\mathbf{2}}$ & $\boldsymbol{\xi}_{\mathbf{1}}$ & $\boldsymbol{\xi}_{\mathbf{2}}$ & $\begin{array}{c}\text { Fracture energy } \\
(\mathbf{N} / \mathbf{m m})\end{array}$ & $\begin{array}{c}\text { Tensile strength } \\
(\mathbf{M P a})\end{array}$ \\
\hline \multirow{2}{*}{ PS0.5 } & PP0.5 & 1.20 & 0.45 & 0.10 & 0.5 & 1.55 & 1.28 \\
& SS0.5 & 1.05 & 0.60 & 0.15 & 0.5 & 2.05 & 1.38 \\
& & & & & & & \\
PS1 & PP1 & 0.80 & 0.90 & 0.10 & 0.8 & 1.06 & 2.10 \\
& SS2 & 0.70 & 1.40 & 0.15 & 0.8 & 2.11 & \\
& & & & & & & 2.20 \\
PS2 & PP2 & 0.30 & 0.80 & 0.10 & 0.7 & 1.00 & 2.85 \\
\hline
\end{tabular}

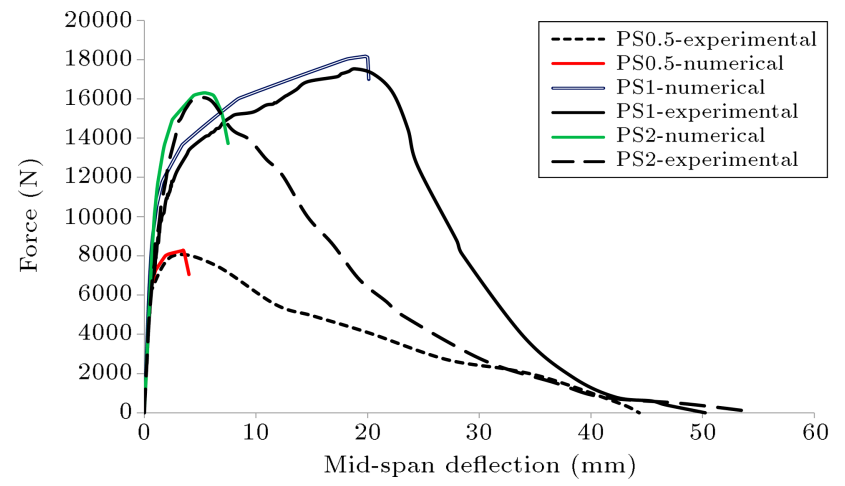

Figure 9. Force vs. deflection of experimental and numerical results [5].

mode I. By conducting the inverse analysis, the values of fracture mode I crack were obtained and listed in Table 2. Additionally, the numerical results attained by execution of inverse analysis are indicated in Figure 9. As depicted in Figure 9, there was a good agreement between numerical and experimental results. Moreover, crack patterns of the numerical FE models were compared with the experimental results in Figure 5, in which the failures observed in the numerical simulations were consistent with the experimental results and the FE models well captured the failures of the tested beams. The crack patterns are represented in Figure 5, in which the red, cyan, and green colors represent the cracks in opening, reopening, and closing processes, respectively.

The numerical results confirm that the used smeared constitutive model for simulating the reinforced layers of beams was an appropriate model to predict the structural behavior of beams; moreover, their failures were well captured through FE models. In this regard, for strengthening the beams made with geopolymer concrete, the smeared constitutive model was employed to simulate the DHCC layers under flexural loading. Moreover, the numerical results confirmed that using a perfect bond to model the transition layer between layers could be a proper assumption to capture structural behavior and crack patterns of beams up to ULS. Thus, a perfect bond was used to model the transition zone between the thin fiber-reinforced concrete plates and geopolymer concrete beams.

\section{Numerical simulations of the strengthened geopolymer concrete beams with DHCC layers}

In the next stage of the present study, after assuring the accuracy and efficiency of the smeared constitutive model to predict structural behavior and crack patterns, the DHCC layers with deflection hardening behavior and beams with brittle behavior of plain geopolymer concrete were numerically modeled in the FEMIX software and, through execution of inverse analysis, the parameters of the fracture mode I of FE models were obtained by calibrating the numerical results with experimental results.

Like the simulated RC beams in Section 5, plane stress finite element adopted 2D planar element to simulate DHCC, plain beams made with geopolymer concrete, and strengthened beams. In the FE models, beams made with plain geopolymer concrete and DHCC layer were modeled using finite element mesh of 400 and 320 plane stress elements of 8 nodes, with a Gauss-Legendre of $2 \times 2$ integration scheme, respectively. Distributed and TPB load conditions were imposed on beams for assessing the flexural performance of the DHCC layer and beams made with geopolymer concrete, respectively. A displacement-controlled loading was applied to the strengthened beams through a distributed load condition with $100 \mathrm{~mm}$ of width and $1000 \mathrm{~mm}$ of length. These dispositions were copied in the numerical models. The total applied deflection was divided into a series of deflection increments. Newton method iterations provided convergence, within tolerance limits, at the end of each deflection increment. As indicated in Figure 10, the compressive strengths of reinforced layers were experimentally recorded in [9] and these values were used in simulating FE models.

To the best of the authors' knowledge, there is only one study in [20] related to strengthening of concrete beams (made with OPC) by using geopolymer mortar plates attached to beams through using some 


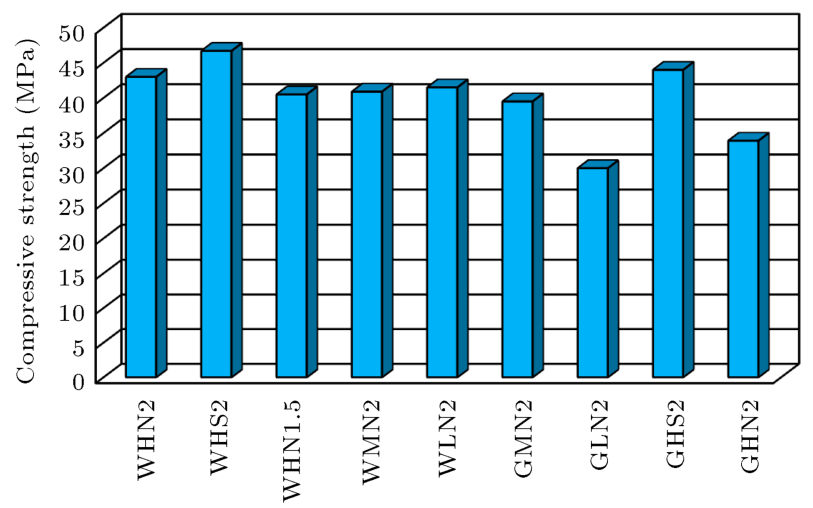

Figure 10. Recorded compressive strength for reinforced layers [9].

CFRP sheets. Employing this strategy led to a weak bond among geopolymeric mortar plates, CFRP sheets, and concrete beams. The previous studies in $[3-5,7]$ indicated that not using composite layers in the transition zone improves the bond between cementitious layers. This can be attributed to further introduction of interfaces between layers.

To the best knowledge of the authors, there is no study that reports using enlargement technique in strengthening plain beams made with the geopolymer concrete. Thus, no experimental and numerical information could be found for modeling the transition zone between the geopolymer concrete and DHCC layer. However, since the results obtained in Section 5.1 and the previous studies in $[3-7,16]$ confirmed that the transition layer could be modeled by a perfect bond between two concrete layers, in the FE models, a perfect bond was used for attaching the fiber-reinforced plates to the plain geopolymer concrete beam.

Table 3 lists the values obtained from implementation of an inverse analysis to define the trilinear tensile diagram of the DHCC layers and geopolymer concrete. Moreover, Figure 11 represents the experimental and numerical load versus deflection responses of the DHCC layer under distributed load and beams made with geopolymer concrete under TPB load. The gathered results in Figure 11 indicate that the numerical results are in a significantly good agreement with the experimental results. According to the obtained results, the proposed FE models could predict the structural behavior of the DHCC layers and beams. A comparison between the numerical and experimental results was carried out and listed in Table 4, including ultimate load capacity $(F)$, deflection $\left(D_{u}\right)$, and ductility $(\mu)$. With respect to the results presented in Table 4 , it can be concluded that the adopted constitutive models for predicting flexural behavior of fiber-reinforced mortar could well capture the structural behavior.

In this study, the ductility was computed by dividing the ultimate deflection, where the failure crack was formed; the applied load starts decreasing $\left(D_{u}\right.$ in Figure 1(a)) to the maximum deflection in linear behavior where the first crack is formed $\left(D_{y}\right.$ in Figure 1(a)).

\subsection{Results of numerical simulations of the strengthened beams with fiber-reinforced layers}

Mechanical properties of fiber-reinforced layers are significantly governed by the type and content of

Table 3. Obtained values from execution of inverse analysis to determine the tensile diagram.

\begin{tabular}{ccccccc}
\hline Specimen designation & $\boldsymbol{\alpha}_{\mathbf{1}}$ & $\boldsymbol{\alpha}_{\mathbf{2}}$ & $\boldsymbol{\xi}_{\mathbf{1}}$ & $\boldsymbol{\xi}_{\mathbf{2}}$ & $\begin{array}{c}\text { Fract ure energy } \\
(\mathbf{N} / \mathbf{m m})\end{array}$ & $\begin{array}{c}\text { Tensile strength } \\
\text { (MPa) }\end{array}$ \\
\hline WHN1.5 & 1.10 & 0.50 & 0.200 & 0.40 & 0.100 & 2.65 \\
WHN2 & 1.13 & 0.50 & 0.200 & 0.40 & 0.200 & 3.20 \\
WHS2 & 1.05 & 0.50 & 0.200 & 0.40 & 0.100 & 2.80 \\
WMN2 & 1.08 & 0.50 & 0.200 & 0.40 & 0.110 & 2.70 \\
WLN2 & 1.05 & 0.50 & 0.200 & 0.40 & 0.100 & 2.83 \\
GMN2 & 1.17 & 0.50 & 0.165 & 0.35 & 0.135 & 3.40 \\
GLN2 & 1.08 & 0.78 & 0.100 & 0.85 & 0.180 & 3.58 \\
GHS2 & 0.72 & 0.20 & 0.110 & 0.12 & 0.710 & 2.75 \\
GHN2 & 1.30 & 0.45 & 0.090 & 0.40 & 0.120 & 3.25 \\
Plain geopolymer concrete & 0.60 & 0.20 & 0.180 & 0.35 & 0.100 & 1.80 \\
\hline
\end{tabular}

Table 4. Comparison of the numerical and experimental results.

\begin{tabular}{cccccccccc}
\hline & WHN2 & WHS2 & WHN1.5 & WMN2 & GHN2 & GMN2 & GLN2 & GHS2 & WLN2 \\
\hline$\frac{F_{\text {Exp }}}{F_{\text {Num }}}$ & 1.02 & 1.02 & 0.98 & 1.00 & 0.98 & 0.95 & 1.01 & 1.06 & 1.00 \\
$\frac{\left(D_{u}\right)_{\text {Exp }}}{\left(D_{u}\right)_{\text {Num }}}$ & 1.01 & 1.00 & 0.93 & 1.00 & 1.03 & 1.00 & 1.02 & 1.00 & 1.00 \\
$\frac{\mu_{\text {Exp }}}{\mu_{\text {Num }}}$ & 1.11 & 1.00 & 0.90 & 1.00 & 1.03 & 1.00 & 1.02 & 0.60 & 1.00 \\
\hline
\end{tabular}




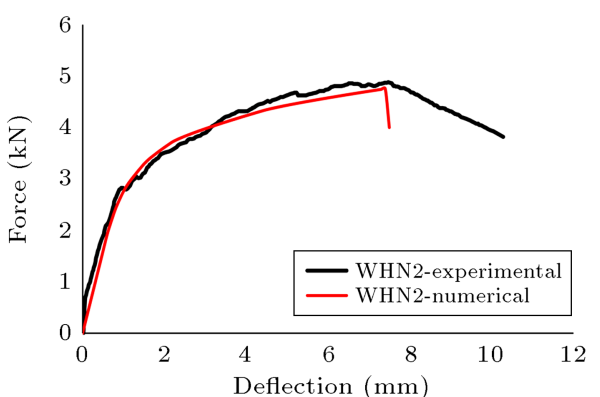

(a) WHN2

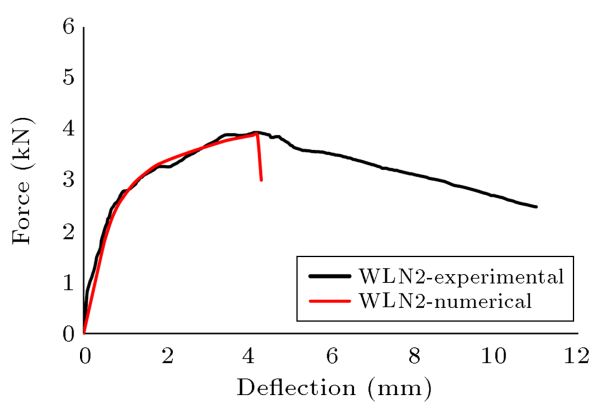

(c) WLN2

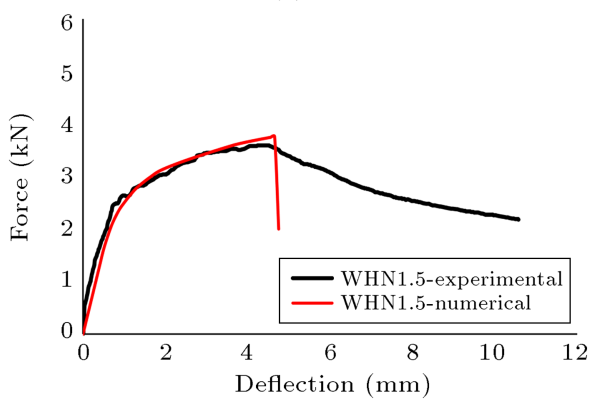

(e) WHN1.5

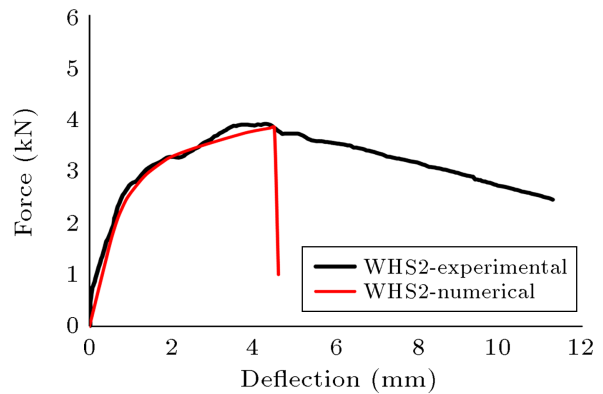

(b) WHS2

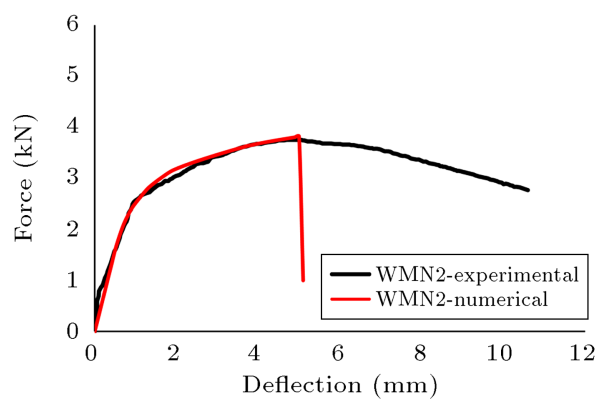

(d) WMN2

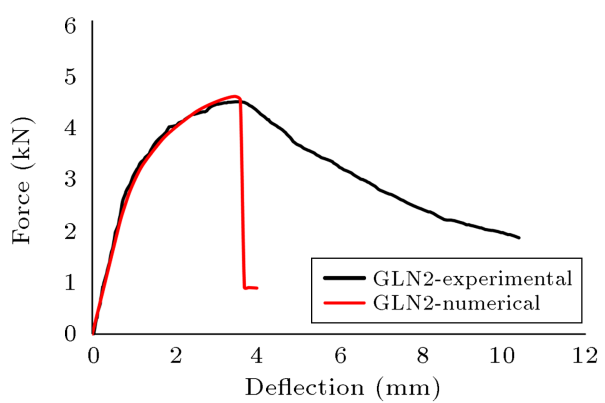

(f) GLN2

Figure 11. Validation of the numerical results with experimental results for some fiber reinforced beams.

fibers and the interface at fiber/matrix bond [21,22]. In this regard, using different fiber-reinforced layers with different flexural and compressive properties to strengthen plain beams leads to different efficiencies obtained for the strengthened beams. Accordingly, the plain beams made with geopolymer concrete were numerically strengthened by using different thin fiberreinforced mortars. The numerical results obtained from the strengthened beams are depicted in Figure 12. Moreover, effects of adding fiber-reinforced mortar layers on ultimate load capacity, ultimate deflection, and ductility of the strengthened beams are depicted in Figure 13. Based on the obtained results, adding fiber-reinforced layers to the beams resulted in increase in the load capacity, deflection, and ductility of the beams. Accordingly, adding a layer of GHN2 to the beams led to increase in ultimate load and its corresponding deflection by about 8.5 and 4.5 times, respectively. Moreover, using a layer of GMN2 to strengthen the beams led to increase in ultimate load and its corresponding deflection by about 8 and 4 times, respectively. Based on the numerical results, it was

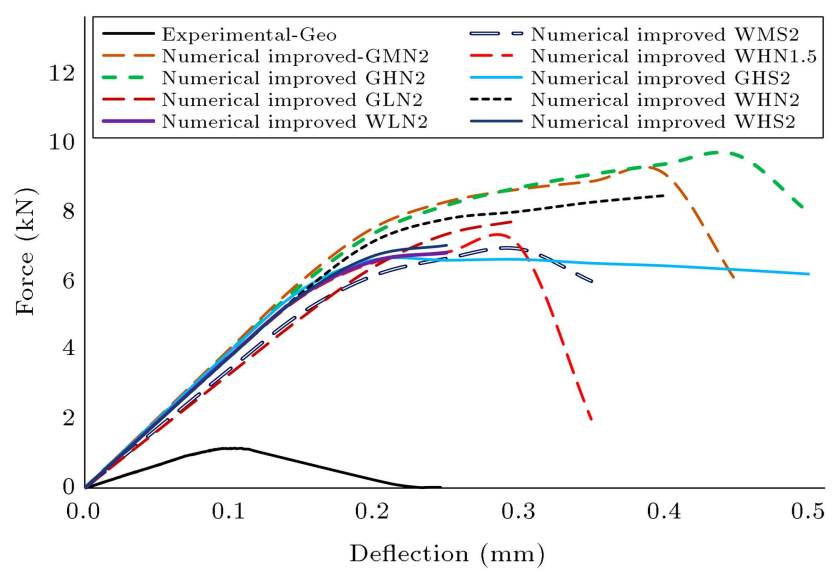

Figure 12. Numerical results obtained from strengthening the plain beams with thin fiber-reinforced mortar layers.

interestingly revealed that strengthening beams by the use of a hardening deflection behavior with superior flexural properties did not necessarily result in obtaining the best structural performance for the strength- 


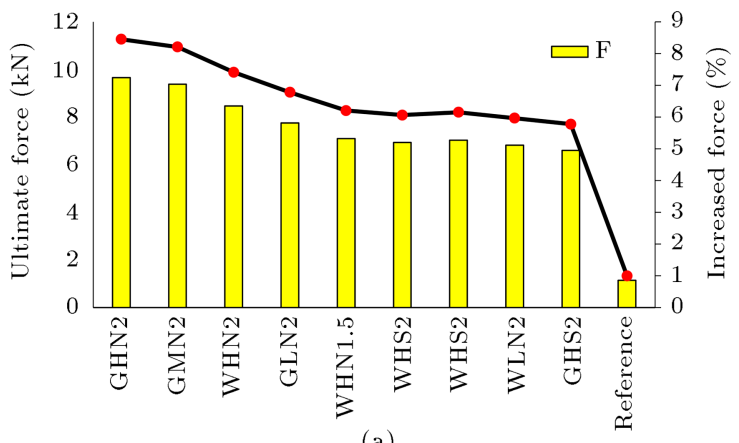

(a)

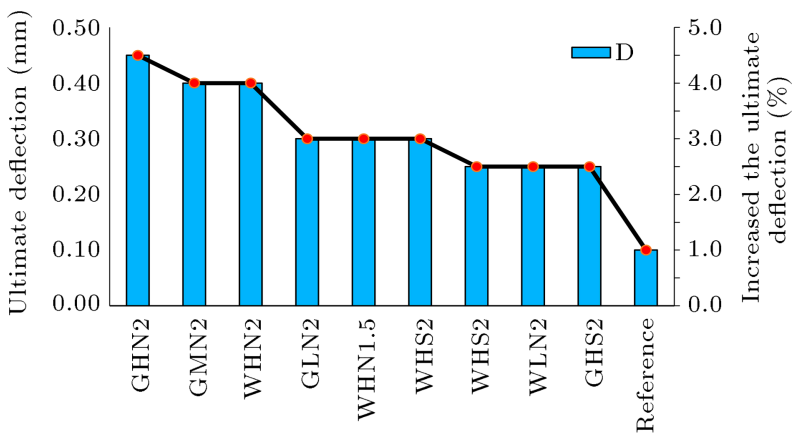

(b)

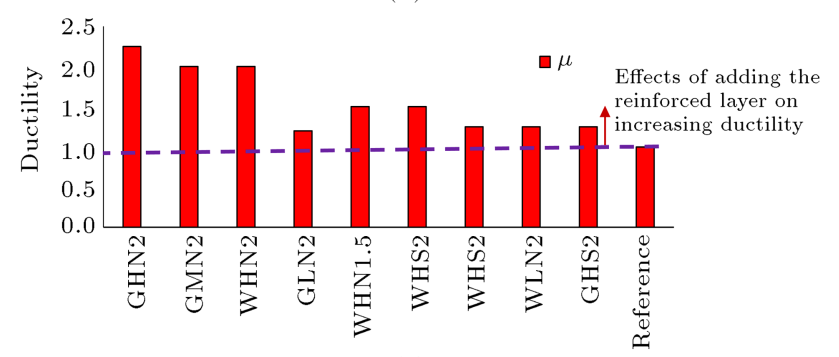

(c)

Figure 13. Effects of adding fiber-reinforced layers on (a) the ultimate force, (b) the ultimate deflection, and (c) ductility.

ened beams. For instance, the best flexural performance was recorded for specimen WHN2, while the best flexural performance in the strengthened beams was registered for beams to which GHN2 was added.

In general, adding a thin fiber-reinforced layer to a beam made with plain geopolymer concrete causes the structural performance of the beams to be enhanced in terms of the ultimate load capacity, ultimate deflection, and ductility. According to the results, this strengthening method is also effective in achieving greater structural enhancement in terms of the ultimate load capacity of beams.

The crack patterns of some strengthened beams are obtained through the execution of numerical simulations and depicted in Figure 14. Comparing the formed cracks in Figures 4 and 14 reveals that using a deflection-hardening layer for strengthening the beams leads to more effective mobilization of the tensile capacity and enhancement of the flexural performance.

Moreover, the effects of increasing compressive

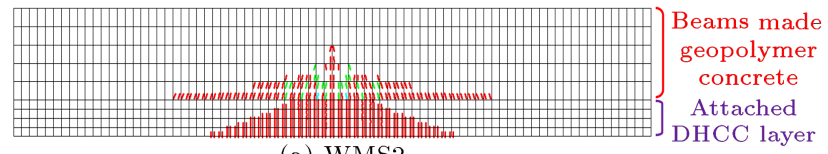

(a) WMS2

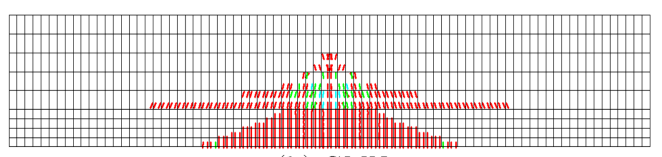

(b) GMN2

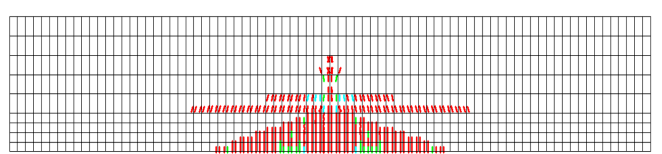

(c) WHN1.5

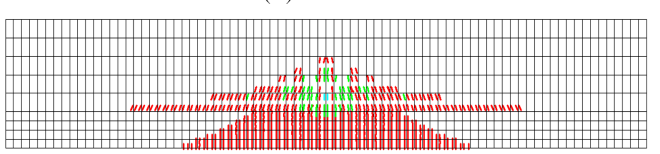

(d) GHN2

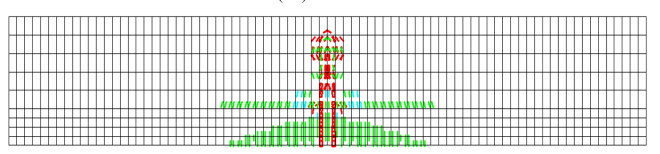

(e) GHS2

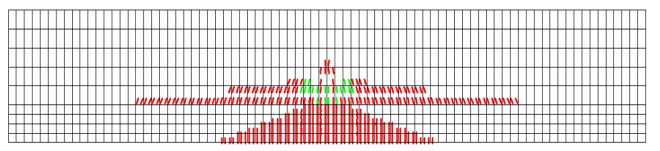

(f) GLN2

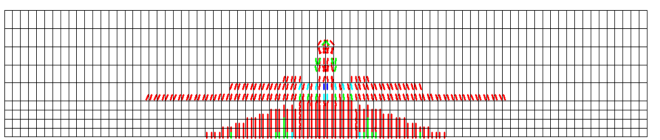

(g) WHG2

Figure 14. Formed numerical crack patterns in some strengthened beams with a thin fiber-reinforced layer.

strength of geopolymer concrete on the structural behavior of the strengthened beams were also investigated. The compressive strength of geopolymer concrete increased from $30 \mathrm{MPa}$ to $60 \mathrm{MPa}$. Based on the previous studies in [20,23-25], the compressive strength of geopolymer concrete does not exceed $60 \mathrm{MPa}$ when being used for engineering applications. As indicated in Figure 15, increasing the compressive strength of geopolymer concrete resulted in increasing the load carrying capacity and ultimate deflection of the strengthened beams. The maximum increases in the ultimate force and deflection were approximately recorded as $35 \%$ and $40 \%$, respectively, for the strengthened beams with WLN2.

\section{Conclusions}

This paper presents a numerical study on strengthening the beams made with geopolymer concrete, using fiberreinforced thin layers with high ductility numerically added to the beams. The following results are highlighted: 


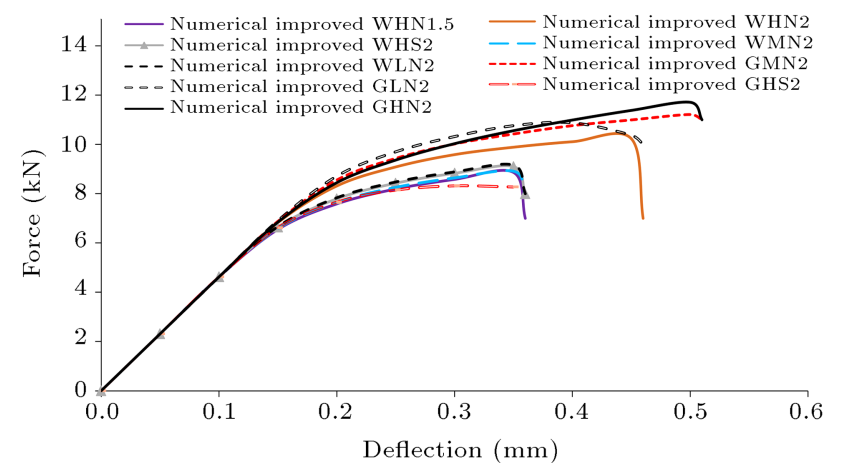

(a)

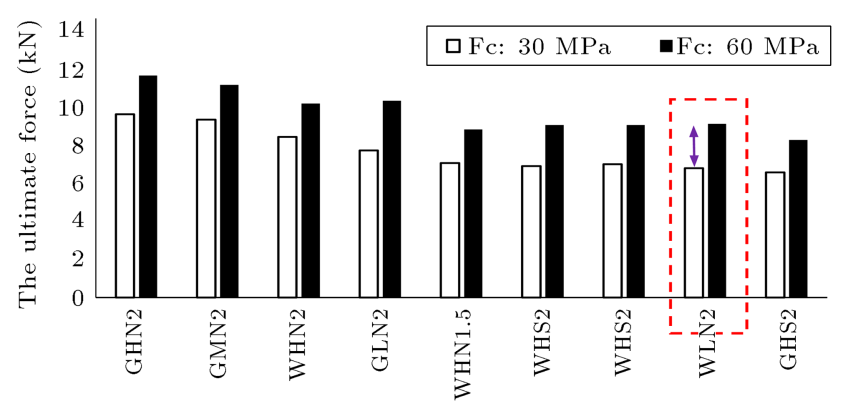

(b)

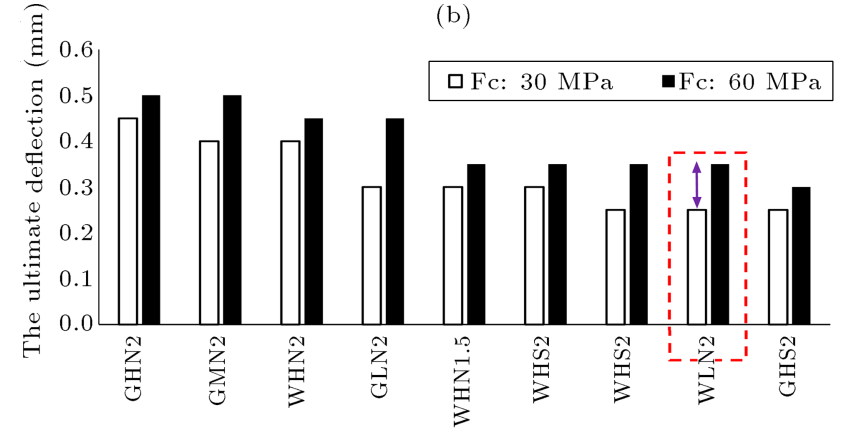

(c)

Figure 15. Effect of increasing compressive strength of geopolymer concrete on (a) the flexural performance of the strengthened beams with thin fiber-reinforced mortar layers, (b) the ultimate force of the strengthened beams, and (c) the ultimate deflection of the strengthened beams.

1. The adopted multi-directional fix smeared crack constitutive model well captured the structural behavior and failure modes of the tested beams;

2. Based on the obtained numerical results, using perfect bond to simulate the transition zone between the DHCC layer and plain geopolymer concrete for transferring shear stresses could be a proper assumption in the numerical modeling;

3. Adding a thin fiber-reinforced layer to the beams improved the ultimate load capacity, ultimate deflection, and ductility in comparison with unstrengthened beam, in such a way that the maximum improvement in the flexural performance of the strengthened beams was observed in the ultimate load capacity;
4. Strengthening beams using a deflection hardening layer with superior flexural properties did not necessarily result in obtaining the best structural performance for the strengthened beams;

5. Using a deflection-hardening layer for strengthening the beams led to more effective mobilization of the tensile capacity of the beams;

6. Increasing the compressive strength of geopolymer concrete resulted in increasing the ultimate force and deflection of the strengthened beams.

\section{References}

1. Abdollahnejad, A., Hlavacek, P., Miraldo, S., PachecoTorgal, F. and Luís Barroso de Aguiar, J. "Compressive strength, microstructure and hydration products of hybrid alkaline cements", Materials Research, 17, pp. 829-837 (2014).

2. Davidovits, J., Comrie, D.C., Paterson, J.H. and Ritcey D.J. "Geopolymeric concretes for environmental protection", ACI ConcrInt, 12, pp. 30-40 (1990).

3. Ghasemi Naghibdehi, M., Sharbatdar, M.K. and Mastali, M. "Repairing reinforced concrete slabs using composite layers", Materials and Design, 58, pp. 136144 (2014).

4. Iskhakov, I., Ribakov, Y., Holschemacher, K. and Mueller, T. "High performance repairing of reinforced concrete structures", Materials and Design, 44, pp. 216-222 (2013).

5. Ghasemi Naghibdehi, M., Mastali, M., Sharbatdar, M.K. and Ghasemi Naghibdehi, M. "Flexural performance of functionally graded RC cross-section with steel and PP fibres", Magazine of Concrete Research, 66, pp. 219-233 (2014).

6. Mastali, M., Ghasemi Naghibdehi, M., Naghipour, M. and Rabiee, S.M. "Experimental assessment of functionally graded reinforced concrete (FGRC) slabs under drop weight and projectile impacts", Journal of Construction and Building Materials, 95, pp. 296-311 (2015).

7. Iskhakov, I., Ribakov, Y., Holschemacher, k. and Mueller, T. "Experimental investigation of full scale two-layer reinforced concrete beams", Journal of $\mathrm{Me}$ chanics of Advanced Materials and Structures, 21, pp. 273-283 (2014).

8. Mastali, M., Valente, I.B., Barros, J.A. Joaquim and Gonçalves, D. "Development of innovative hybrid sandwich panel slabs: Experimental results", Journal of Composite Structures, 133, pp. 476-498 (2015).

9. Aliasgari, M. "Investigation of tensile capacity of precast glass fiber reinforced concrete panels", Master Thesis, Semnan University, Semnan, Iran (2010).

10. Eduardo, N.B., Pereira, E., Barros, J.A.O. and 
Camões, A. "Steel fiber-reinforced self-compacting concrete: experimental research and numerical simulation", Journal of Structural Engineering, 134, pp. 1310-1321 (2008).

11. Mastali, M., Valente, I.B. and Barros, A.O. Joaquim "Development of innovative hybrid sandwich panel slabs: Advanced numerical simulations and parametric studies", Journal of Composite Structures, 152, pp. 362-381 (2016).

12. Ventura-Gouveia, A. "Constitutive models for the material nonlinear analysis of concrete structures including time dependent effects", PhD Thesis, Dep. Civil Eng., Minho University, Portugal (2011).

13. Rots, J.G. "Computational modeling of concrete fracture", PhD Thesis, Delft University of Technology, The Netherlands (1988).

14. Sena-Cruz, J.M. "Strengthening of concrete structures with near-surface mounted CFRP laminate strips", PhD Thesis, Department of Civil Engineering, University of Minho, Portugal (2004).

15. Barros, A.O. Joaquim, Costa, G.I. and VenturaGouveia, A. "CFRP flexural and shear strengthening technique for RC beams: Experimental and numerical research", Advances in Structural Engineering, 14, pp. 551-573 (2011).

16. Mastali, M., Mastali, M., Abdollahnejad, Z., Ghasemi Naghibdehi, M. and Sharbatdar, M.K. "Numerical evaluations of functionally graded RC slabs", Chinese Journal of Engineering, 2014, Article ID 768956, 20 pages (2014).

17. Martinola, G., Meda, A., Giovanni, A. and Plizzari, Rinaldi Z. "Strengthening and repair of RC beams with fiber reinforced concrete", Journal of Cement and Concrete Composites, 32, pp. $732-739$ (2010).

18. Loreto, G., Leardini, L., Arboleda, D. and Nanni, A. "Performance of RC slab-type elements strengthened with fabric-reinforced cementitious-matrix composites", Journal of Composites for Construction, 18, pp. 1-9, DOI: 10.1061/(ASCE)CC.1943-5614.0000415, A4013003, (2013).

19. Lampropoulos, A.P., Paschalis, S.A., Tsioulou, O.T. and Dritsos, S.E. "Strengthening of reinforced concrete beams using ultra high performance fiber reinforced concrete (UHPFRC)", Journal of Engineering Structures, 106, pp. 370-384 (2016).

20. Pacheco-Torgal, F., Abdollahnejad, Z., Miraldo, S., Baklouti, S. and Ding, Y. "An overview on the potential of geopolymers for concrete infrastructure rehabilitation", Journal of Construction and Building Materials, 36, pp. 1053-1058 (2012).

21. Mastali, M., Dalvand, A. and Sattarifard, A.R. "The impact resistance and mechanical properties of reinforced self-compacting concrete with recycled glass fiber reinforced polymers", Journal of Cleaner Production, 124, pp. 312-324 (2016).

22. Mastali, M. and Dalvand, A. "The impact resistance and mechanical properties of self-compacting concrete reinforced with recycled CFRP pieces", Journal of Composite Part B: Engineering, 92, pp. 360-376 (2016).

23. Vasconcelos, E., Fernandes, S., Barroso de Aguiar, J.L. and Pacheco-Torgal, F. "Concrete retrofitting using metakaolin geopolymer mortars and CFRP", Journal of Construction and Building Materials, 25, pp. 32133221 (2011).

24. Pacheco-Torgal, F., Miraldo, S., Ding, Y., Abdollahnejad, Z. and Labrincha, J.A. "Are geopolymers more suitable than Portland cement to produce high volume recycled aggregates HPC?", Journal of Construction and Building Materials, 36, pp. 1048-1052 (2012).

25. Pacheco-Torgal, Abdollahnejad, Z., Camões, A.F., Jamshidi, M. and Ding, Y. "Durability of alkaliactivated binders: a clear advantage over Portland cement or an unproven issue?", Journal of Construction and Building Materials, 30, pp. 400-405 (2012).

\section{Biographies}

Mohammad Mastali is a researcher at university of Minho, Portugal. He is a member of the Institute for Sustainability and Innovation in Structural Engineering (ISISE). His main research interests are concerned with fiber reinforced-concrete, geopolymer concrete, durability of concrete, and finite element modeling of RC structures. He is author and co-author of several papers in international and national journals and conferences.

Majid Mastali is a graduate student at University of Western Michigan University in USA. His main research interests are related to concrete, infrastructures, and project management of RC structures. He is author and co-author of several papers in international and national journals and conferences.

Zahra Abdollahnejad has been a researcher at university of Minho, Portugal, since 2016. She is also a member of Centre of Excellence in Engineered Fibre Composites (CEEFC) in Australia. Her main research interests are concerned with green lightweight concrete, geopolymer concrete, high performance fiber reinforced concrete, durability of concrete, and finite element modeling of RC structures. She is author and co-author of several papers in international and national journals and conferences.

Ahmad Dalvand is an Assistant Professor at University of Lorestan, Iran. His main research interests are concerned with fiber-reinforced concrete and finite element modeling of RC structures. He is author and co-author of several papers in international and national journals and conferences. 